\title{
Games for the Assessment and Treatment of Mental Health
}

\author{
Regan L. Mandryk \\ Dept. of Computer Science, \\ University of Saskatchewan, \\ Saskatoon, SK, CA \\ regan@cs.usask.ca \\ Max V. Birk \\ Dept. of Computer Science, \\ University of Saskatchewan, \\ Saskatoon, SK, CA \\ max.birk@usask.ca \\ Adam Lobel \\ Swiss Center for Affective \\ Sciences, \\ University of Geneva, \\ Genève, $\mathrm{CH}$ \\ adam.lobel@unige.ch \\ Marieke van Rooij \\ Behavioral Science Institute, \\ Radbound University, \\ Nijmegen, NL \\ m.vanrooij@bsi.ru.nl \\ Isabela Granic \\ Behavioral Science Institute, \\ Radbound University, \\ Nijmegen, NL \\ i.granic@pwo.ru.nl

\section{Vero Vanden Abeele} \\ e-Media Lab \\ KU Leuven - University of Leuven, \\ Leuven, BE \\ vero.vandenabeele@kuleuven.be
}

Permission to make digital or hard copies of part or all of this work for personal or classroom use is granted without fee provided that copies are not made or distributed for profit or commercial advantage and that copies bear this notice and the full citation on the first page. Copyrights for thirdparty components of this work must be honored. For all other uses, contact the owner/author(s). Copyright is held by the author/owner(s). CHI PLAY'17 Extended Abstracts, October 15-18, 2017, Amsterdam, Netherlands

(C) 2017 Copyright is held by the owner/author(s).

ACM ISBN 978-1-4503-5111-9/17/10.

https://doi.org/10.1145/3130859.3131445

\section{Author Keywords}

Games; mental health; treatment; assessment

\section{ACM Classification Keywords}

H.5.m. Information interfaces and presentation (e.g. $\mathrm{HCI}$ ): Miscellaneous

\begin{abstract}
The prevalence of mental illness is on the rise [7] -

$18 \%$ of adults in the USA had a diagnosed mental illness in 2014 [31]; however, 57\% of adults with mental illness in the USA do not receive treatment [28]. Untreated mental illness has serious consequences. The cost of depression and anxiety alone is estimated at $\$ 1$ trillion per year in US dollars [8]. In addition to these financial costs, people experience costs to their well-being that range from a lower quality of life [39] to a loss of life [32]. Although mental health care systems can provide support, there are several reasons why people may not receive treatment [40]. For example, there are not enough trained professionals to provide for those in need; access to treatment is lower for people who live in underpopulated or lower-income areas [28]; and people with mild impairment lack access to a system that is already burdened from treating those with more severe issues.
\end{abstract}




\section{Biographies}

Regan Mandryk co-directs the Interaction Lab. With over 150 papers that have been cited over 5700 times, Regan creates novel ways of understanding player experience in partnership with multiple industrial and internationa collaborators. She also develops and evaluates games for health, and games that foster interpersonal relationships. Regan has played a central role in the growth of CHI PLAY and the games community within SIGCHI.

Isabela Granic leads the Games for Emotional and Mental Health Lab and is CEO of the Playnice Institute. She bridges developmental science and game design in order to create a suite of evidencebased games that can be widely disseminated to build children's emotional resilience. Her seminal article (with Lobel) on the benefits of playing video games in American

Psychologist (2014) has already been cited over 400 times.
These limitations in access to treatment cannot be addressed solely by growing the existing mental health system [10]; rather, the solution requires a variety of approaches, including a scaling in delivery mechanisms $[8]$ that involve digital solutions $[6,15,33]$. There are already examples of digital interventions in the domain of mental health (see [26] for overview), whose success offer promise for use in self-help or as an adjunct to clinical treatment [17].

Effective designs of digital interventions for mental health necessitate several considerations. For example, patients need to adhere to the intervention repeatedly over the long term; assessments need to be standardized in their administration; solutions should be accessible to people from different geographic locations and demographic populations; and should be customizable for individual patients. These factors that describe good intervention design - i.e., accessible, motivating, broadly appealing, and tailored- also characterize the space of digital games [3].

\section{Games for Mental Health}

People play a lot of games; four out of five American households own a device used to game [41], and internationally, the game market is expected to exceed $\$ 102$ billion by 2017 [42]. As such, researchers have started to question what makes games so compelling to play. Digital game researchers have started to deconstruct how satisfaction of needs during play [36] leads to game enjoyment for different players $[2,20,36]$ and in varying gameplay scenarios $[1,18,19]$. Others have explored how to leverage these game design elements to motivate people in non-game contexts - a process called gamification $[11,30]$. There are already several examples of gamified interventions in the context of mental health (e.g.

$[13,22,23,27,29,37,38])$. Furthermore, games offer an opportunity for improving mental health at a largescale as it is known that people use games to recover from noxious moods. Mood repair through escapism is included in validated scales on motivations for play [12] and game addiction [25], and surveys have found that both adults [19,34] and children [14] report mood regulation as a major motivation for play. Several researchers have started to examine how games facilitate recovery from the stress of life $[4,5,9,35]$. Finally, researchers have suggested that digital games provide an opportunity for improved emotion regulation [21], for example, by rewarding players who downregulate negative affect [16].

The community for research on video games for assessment and intervention for mental health spans multiple disciplines, from cognitive sciences, computer science, and interaction design, to psychology, neurobiology, and medicine [24]. The goal of this workshop is to bring together an international group of researchers to discuss the current state of games for mental and formulate a plan for moving this research agenda forward in the CHI PLAY community.

\section{Objectives \& Expected Outcomes}

The workshop has the following objectives:

- $\quad$ Bring together an international group of researchers

- Create an overview of current game-based approaches for the assessment and interventions of mental health

- $\quad$ Discuss interests and directions for innovation

- Identify overlap between research groups 


\section{Biographies}

Max Birk is a PhD Student in Computer Science with a background in experimental psychology, psychophysiology, games user research, and human-computer interaction; Max has a variety of experience, all connected by his interest in games and has been involved as an $\mathrm{AC}$ and organizer of several CHI PLAY and $\mathrm{CHI}$ conferences.

Marieke van Rooij is an Assistant Professor at the Behavioral Science Institute. Her background in applied math and experimental psychology spawned her interest in the detection of individual patterns of change in behavioural and physiological data generated by games.
- $\quad$ Define a plan for knowledge exchange and collaboration between groups - e.g., through internships, research visits, invited presentations, and formal and informal collaborations

Participants will have the opportunity to gain knowledge about the state of the international research community interested in game-based solutions for mental health. There will be opportunities to meet peers in different stages of their careers and discuss opportunities for future collaborations to consolidate a community in this emerging area.

The community will benefit from the growth of a novel, timely, relevant, and underexplored research area that opens possibilities for interdisciplinary research at the intersection of game design and mental health.

\section{Planned Activities}

The workshop will be run as a single day event, split into 4 units. The first unit will be dedicated to the introduction of the participants, including a short presentation of the submitted work. During the second unit, participants will discuss and capture current progress and challenges of game-design for mental health, considering aspects of clinical, computational, and design demands. In the third unit, participants will discuss potential solutions for the challenges identified in unit two. In unit four, participants will summarize the progress made and discuss potential collaborations. We may also combine with the workshop on games for positive psychology in unit four.

Coffee breaks and lunch will be used for networking and community development, which will be continued during a workshop dinner.
The outcome of the workshop will be summarized, documented and made available for the community; potentially in the form of a special issue of a journal. Furthermore, the community will benefit through future workshops and collaborations that will inevitably result from this workshop.

\section{Participants}

Participants are encouraged to submit a 2 to 4-page position paper, including a biography. Papers will be reviewed by the organizers and accepted papers will be presented on the website as part of the workshop proceedings. Position papers on the following topics are encouraged: game-design, evaluation techniques, technologies, protocols, and best-practices for gamebased interventions and assessment of mental health and emotional wellness.

We have identified multiple international groups within and outside of the CHI Play community who are potential attendees. We are in communication with research groups from Europe, Australia, and North America who are interested in attending the workshop. We assume that around 20 experts from multiple institutions will submit proposals and attend the workshop. The success of the Symposium on Computing and Mental Health at CHI 2016 and 2017 provides an indication of the current interest in technical solutions for mental health issues.

\section{Conclusions}

This workshop will form the foundation for connecting a growing group of researchers both within and outside of the CHI PLAY community interested in the use of games for mental health and emotional wellness. 


\section{Biographies}

Adam Lobel is a postdoctoral researcher and game designer at the Swiss Center for Affective Sciences in Geneva, Switzerland. His PhD research in Psychology focused on the emotion regulation benefits of video gaming.

\section{Vero Vanden Abeele is a}

professor at the Faculty of Engineering Technology, KU Leuven. Her research relates to game-based assessment and gamification of selfassessments, with a specific focus on understanding attentional and motivational processes to increase adherence and reliability of measurement. Vero has been involved in the international game community (chairing Fun and Games 2010), and is papers chair of CHI PLAY 2016 and CHI PLAY 2017.

\section{References}

1. Birk M, Mandryk RL. Control your game-self: effects of controller type on enjoyment, motivation, and personality in game. In: Proceedings of the SIGCHI Conference on Human Factors in

Computing Systems; Apr 27-May 2, 2013; Paris, France. 685-694. ACM. DOI: $10.1145 / 2470654.2470752$

2. Birk, MV, Mandryk RL, Miller MK, Gerling KM. How self-esteem shapes our interactions with play technologies. In: Proceedings of the 2015 Annual Symposium on Computer-Human Interaction in DOI: $10.1145 / 2793107.2793111$

3. Birk MV, Mandryk RL. 2016. The Benefits of Digital Games for the Assessment and Treatment of Mental Health. Presented at the CHI 2016 Workshop Computing in Mental Health. May 8, 2016; San Jose, CA, USA.

4. Bowman ND, Tamborini R. "In the Mood to Game": Selective exposure and mood management processes in computer game play. New Media \& Society. 2015;17(3):375-93. DOI: 10.1177/1461444813504274

5. Bowman ND, Tamborini R. Task demand and mood repair: The intervention potential of computer games. New Media \& Society. 2012;14(8):1339-57. DOI: $10.1177 / 1461444812450426$

6. Calvo RA, Dinakar K, Picard R, and Maes P. Computing in mental health. In: Proceedings of the 2016 CHI Conference Extended Abstracts on Human Factors in Computing Systems. May $7-12$, 2016; San Jose, CA, USA. 3438-3445. ACM. DOI: $10.1145 / 2851581.2856463$

7. Behavioral health trends in the United States: Results from the 2014 National Survey on Drug Use and Health. 2015. Substance Abuse and Mental Health Association Service Administration. https://www.samhsa.gov/data/sites/default/files/N
SDUH-FRR1-2014/NSDUH-FRR1-2014.pdf. Accessed February 24, 2017.

8. Chisholm D, Sweeny K, Sheehan P, et al. Scalingup treatment of depression and anxiety: a global return on investment analysis. Lancet Psychiatry. 2016;3(5):415-24. PMID: 27083119

9. Collins, E, and Cox, A.L. Switch on to games: Can digital games aid post-work

recovery?. International Journal of Human-

Computer Studies 72, no. 8 (2014): 654-662.

10. Cuijpers $P$, Riper $H$, Andersson G. Internet-based treatment of depression. Curr Opin Psychol. 2015 Aug 31;4:131-5. DOI: 10.1016/j.copsyc. 2014.12 .026

11. Deterding S, Dixon D, Khaled R, Nacke L. From game design elements to gamefulness: defining gamification. In: Proceedings of the 15th international academic MindTrek conference: Envisioning future media environments. Sep 28, 2011; Tampere, Finland. 9-15. ACM. DOI 10.1145/2181037.2181040

12. De Grove F, Cauberghe V, Van Looy J. Development and validation of an instrument for measuring individual motives for playing digital games. Media Psychology. 2016 Jan 2;19(1):10125. DOI: 15213269.2014 .902318

13. Dennis TA, O'toole L. Mental Health on the Go: Effects of a Gamified Attention Bias Modification Mobile Application in Trait Anxious Adults. Clin Psychol Sci. 2014;2(5):576-590. PMID: 26029490

14. Ferguson $\mathrm{CJ}$, Olson CK. Friends, fun, frustration and fantasy: Child motivations for video game play. Motiv Emot. 2013 Mar 1;37(1):154-64. DOI: $10.1007 / \mathrm{s} 11031-012-9284-7$

15. Gillan CM, Daw ND. Taking Psychiatry Research Online. Neuron. 2016;91(1):19-23. PMID: 27387647 
16. Granic I, Lobel A, Engels RC. The benefits of playing video games. Am Psychol. 2014;69(1):6678. PMID: 24295515

17. Griffiths KM, Farrer L, Christensen $H$. The efficacy of Internet Interv for depression and anxiety disorders: a review of randomised controlled trials. Med J Aust. 2010;192(11):S4-11. PMID: 20528707

18. Gerling KM, Birk M, Mandryk RL, Doucette A. The effects of graphical fidelity on player experience. In: Proceedings of International Conference on Making Sense of Converging Media. Oct 1-4, 2013; Tampere, Finland. 229-37. ACM. DOI:

$10.1145 / 2523429.2523473$

19. Hilgard J, Engelhardt CR, Bartholow BD. Individual differences in motives, preferences, and pathology in video games: the gaming attitudes, motives, and experiences scales (GAMES). Front Psychol. 2013;4:608. PMID: 24058355

20. Johnson D, Gardner J, Sweetser P. Motivations for videogame play: Predictors of time spent playing. Computers in Human Behavior. Oct 31, 2016;63:805-12. DOI 10.1016/j.chb.2016.06.028

21. Johnson $D$, Wyeth $P$, Sweetser $P$. The peoplegame-play model for understanding videogames' impact on wellbeing. In: 2013 IEEE International Games Innovation Conference (IGIC). Sept 23-25, 2013; Vancouver, BC, Canada. 85-88. IEEE. DOI: 10.1109/IGIC.2013.6659143

22. Kahn J, Ducharme P, Rotenberg A, Gonzalezheydrich J. "RAGE-Control": A Game to Build Emotional Strength. Games Health J. 2013;2(1):53-7. PMID: 26196556

23. Kato PM. Video games in health care: Closing the gap. Rev Gen Psychol. 2010 Jun;14(2):113. DOI: 10.1037/a0019441

24. Li J, Theng YL, Foo S. Game-based digital interventions for depression therapy: a systematic review and meta-analysis. Cyberpsychol Behav Soc Netw. 2014;17(8):519-27. PMID: 24810933
25. Lemmens JS, Valkenburg PM, Peter J. Development and validation of a game addiction scale for adolescents. Media Psychology. 2009,12(1):77-95. DOI: $10.1080 / 15213260802669458$

26. Mandryk, RL and Birk, MV. Toward Game-Based Digital Mental Health Interventions: Player Habits and Preferences. J Med Internet Res, 2017, 19(4). doi:10.2196/jmir.6906

27. Mandryk RL, Dielschneider S, Kalyn MR et al. Games as neurofeedback training for children with FASD. In: Proceedings of the 12th Internationa Conference on Interaction Design and Children. Jun 24-27,2013; New York, NY, USA. 165-172. ACM. DOI: $10.1145 / 2485760.2485762$

28. Mental Health Facts, Stats, and Data. 2016. Mental Health America Web Site.

http://www.mentalhealthamerica.net/issues/statemental-health-america. Accessed February 21, 2017.

29. Merry SN, Stasiak K, Shepherd M, Frampton C, Fleming $T$, Lucassen MF. The effectiveness of SPARX, a computerised self help intervention for adolescents seeking help for depression: randomised controlled non-inferiority trial. BMJ. 2012;344:e2598. PMID: 22517917

30. Nicholson S. A recipe for meaningful gamification. In: Gamification in education and business. 2015; 1-20. Springer International Publishing.

31. Any Anxiety Disorder Among Adults. 2016. National Institute of Mental Health Web Site.

https://www.nimh.nih.gov/health/statistics/prevale nce/any-anxiety-disorder-among-adults.shtml. Archived at: http://www.webcitation.org/6oWHsmmQB. Accessed February 21, 2017

32. Nock MK, Hwang I, Sampson N, et al. Crossnational analysis of the associations among mental disorders and suicidal behavior: findings from the 
WHO World Mental Health Surveys. PLoS Med 2009;6(8):e1000123. PMID: 19668361

33. Regalado A. Why America's Top Mental Health Researcher Joined Alphabet. Technology Review Web Site.

https://www.technologyreview.com/s/541446/whyamericas-top-mental-health-researcher-joinedalphabet/. Archived at:

http://www.webcitation.org/6oWI53FkZ. Accessed February 21, 2017

34. Reinecke L. Games and recovery: The use of video and computer games to recuperate from stress and strain. J Media Psychol. 2009 Jan;21(3):126-42. DOI: $10.1027 / 1864-1105.21 .3 .126$

35. Reinecke L, Klatt J, Krämer NC. Entertaining media use and the satisfaction of recovery needs: Recovery outcomes associated with the use of interactive and noninteractive entertaining media. Media Psychology. 2011 May 31;14(2):192-215. DOI: $10.1080 / 15213269.2011 .573466$

36. Ryan RM, Rigby CS, Przybylski A. The motivational pull of video games: A self-determination theory approach. Motiv and emot. 2006; 1;30(4):344-60. DOI: $10.1007 / \mathrm{s} 11031-006-9051-8$

37. Scholten $H$, Malmberg $M$, Lobel A, Engels RC, Granic I. A Randomized Controlled Trial to Test the Effectiveness of an Immersive 3D Video Game for Anxiety Prevention among Adolescents. PLOS ONE. 2016;11(1):e0147763. PMID: 26816292
38. Schoneveld EA, Malmberg M, Lichtwarck-Aschoff A, Verheijen GP, Engels RC, Granic I. A neurofeedback video game (MindLight) to prevent anxiety in children: A randomized controlled trial. Comput Human Behav. Oct 31, 2016;63:321-33.

39. Skevington SM, Lotfy M, O'connell KA. The World Health Organization's WHOQOL-BREF quality of life assessment: psychometric properties and results of the international field trial. A report from the WHOQOL group. Qual Life Res. 2004;13(2):299310. PMID: 15085902

40. Mental health atlas. 2014. World Health Organization. Dept. of Mental Health, and Substance Abuse.

41. Essential Facts 2015. 2015. Entertainment Software Association Web Site.

http://www.theesa.com/wpcontent/uploads/2015/04/ESA-Essential-Facts2015.pdf. Archived at:

http://www.webcitation.org/6oWIIs1jq. Accessed February 21, 2017.

42. Essential Facts 2014. 2014. Entertainment Software Association Web Site.

http://www.theesa.com/wp-

content/uploads/2014/10/ESA_EF_2014.pdf. Archived at:

http://www.webcitation.org/6oWIN1Siy. Accessed February 21, 2017. 